\title{
Gesture Use in Communication between Mothers and Offspring in Wild Orang-Utans (Pongo pygmaeus wurmbii) from the Sabangau Peat-Swamp Forest, Borneo
}

\section{Andrea Knox, et al. [full author details at the end of the article]}

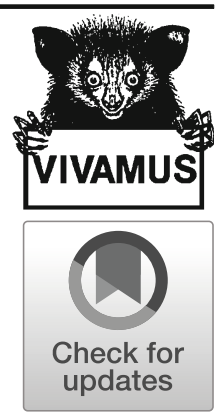

Received: 17 September 2018 / Accepted: 9 May 2019 / Published online: 24 June 2019

(C) The Author(s) 2019

\begin{abstract}
Research on captive and wild great apes has established that they employ large repertoires of intentional gestural signals to achieve desired goals. However, gestural research has focused on African great apes, with orang-utan data limited to a few captive studies. We address this gap by describing gesture use in wild Southwest Bornean orang-utan (Pongo pygmaeus wurmbii) mother and offspring pairs. We conducted focal follows on 16 individuals in the Sabangau peatswamp forest in Borneo, Indonesia. The resulting $681 \mathrm{~h}$ of video footage yielded 1299 communicative signals: 858 vocal signals and 441 gestural signals. Eleven vocal signal types and 21 gesture types met the criteria for inclusion in the repertoire; however, the gestural repertoire did not approach asymptote and further gesture types will likely be identified in the future. Signalers used gestures of any modality in higher frequency when the recipient was paying visual attention, and took the recipient's visual attention into account when selecting gesture modalities. Orang-utans employed hands and arms more than legs and feet in gesturing, but were more flexible in their choice of limb than chimpanzees using the same gestures. Orang-utans were highly responsive to gestural requests, using them to achieve eight goals and, where successful, responding either before gesturing ended or in $<1 \mathrm{~s}$ in $90 \%$ of communications. Our findings on the range of gesture types and impact of visual attention support findings from captive orang-utans; and those on responsiveness and limb use highlight the importance of studying ape communication in the social and ecological context to which it is adapted.
\end{abstract}

Keywords Attention state $\cdot$ Gesture $\cdot$ Pongo $\cdot$ Responsiveness $\cdot$ Signal modality $\cdot$ Vocal

Handling Editor: Joanna M. Setchell.

Electronic supplementary material The online version of this article (https://doi.org/10.1007/s10764-01900095-w) contains supplementary material, which is available to authorized users. 


\section{Introduction}

Nonhuman great apes' (hereafter great apes) use of 60-80 gestures in intentional communication remains the only broad system of communication outside of human language in which there is evidence for widespread and flexible use of goal-directed signals to communicate language-like meaning in everyday social interaction (Graham et al. 2018; Hobaiter and Byrne 2014, 2017; Moore 2014). Great apes employ diverse repertoires of vocal, gestural, and facial signals to communicate a wide range of nuanced information (e.g., bonobos, Pan paniscus: Graham et al. 2017; Pika et al. 2005; chimpanzees, Pan troglodytes: Bard et al. 2017; Fröhlich et al. 2016a, 2016b; Hobaiter and Byrne 2011a, 2011b, 2014; Plooij 1978; Roberts et al. 2012; Tomasello et al. 1985, 1989; gorillas, Gorilla gorilla: Genty et al. 2009; Perlman et al. 2012; Pika et al. 2003; Tanner and Byrne 1999; orang-utans, Pongo: Liebal et al. 2006; crossspecies: Bard and Vauclair 1984; Pollick and de Waal 2007). Recently, researchers have started to describe the way in which apes combine their signals; with gestures, vocalizations, and facial expressions, among other signals, employed in a single communicative system. These studies have highlighted the importance of considering communication holistically (Hobaiter et al. 2017; Liebal et al. 2011; Wilke et al. 2017), as well as blurring the boundary between signal categories (e.g., orang-utans' use of their hands to modify the acoustic properties of some vocalizations: Lameira et al. 2013; Peters 2001).

Vocal behavior has been studied across great ape species in both captive and wild populations (e.g., chimpanzees: Crockford and Boesch 2005; Goodall 1986; Hauser and Wrangham 1987; bonobos: Bermejo and Omedes 1999; de Waal 1988; gorillas: Salmi et al. 2013; orang-utans: Lameira et al. 2015; Wich et al. 2012). However, gestural research efforts have focused mostly on the African great apes, with detailed repertoires described for the gesturing of both captive and wild chimpanzees (e.g., Bard et al. 2014; Hobaiter and Byrne 2011a; Pollick and de Waal 2007; Roberts et al. 2012; Tomasello et al. 1985, 1989), bonobos (e.g., Genty et al. 2014, 2015; Graham et al. 2017; Halina et al. 2013; Pika et al. 2005), and gorillas (Byrne and Tanner 2006; Genty et al. 2009; Pika et al. 2003; Tanner et al. 2006), while gestural research on orang-utans is limited to a few captive studies (Cartmill 2008; Cartmill and Byrne 2007, 2010; Liebal et al. 2006; although cf. Mackinnon 1974 for descriptions of wild orang-utan signals, Bard 1992 for gesture use in free-ranging reintroduced individuals, and Waller et al. 2015 for facial displays).

Great apes show substantial flexibility in the production of their signals, for example showing nuanced audience effects in their vocalizations (audience composition: Crockford et al. 2012; Schel et al. 2013a, 2013b; Slocombe and Zuberbühler 2007) and facial expressions (audience attention: Waller et al. 2015). Unlike either vocal or facial signal repertoires, gestural repertoires contain signals with a range of information modalities (e.g., in the case of gesture: audible, visual, and tactile). All vocal and facial signals contain, respectively, either audiovisual or visual information. However, gestural signals offer signalers flexibility in signal selection relative to the visual attention of their recipient. Great apes can adjust their selection of gesture types to take into account other individuals' ability to receive the information (e.g., Cartmill and Byrne 2007; Cudmore and Galdikas 2012; Hobaiter and Byrne 2011a; Liebal et al. 2004a, 
2004b; Poss et al. 2006; Tomasello et al. 1994), including potential eavesdroppers (Hobaiter et al. 2017).

Studies of communication in captive great apes have provided unique insights into their cognitive capacities, for example, selecting the appropriate modality for their audience's visual attention, showing understanding of the physical basis of gestural communication (e.g., Tomasello et al. 1985, 1989), and showing understanding of recipients' knowledge states (Cartmill and Byrne 2007). However, a captive environment impacts the expression of species-typical behavior (e.g., Hobaiter and Byrne 2011a; Seyfarth and Cheney 2017), and can lead to the regular spontaneous production of behavior rarely, if ever, seen in the wild (chimpanzee pointing: Hobaiter et al. 2013; Leavens et al. 2005b; tool use in gorillas: Fontaine et al. 1995; Lonsdorf et al. 2009).

The study of gestural communication in wild orang-utans provides a general point of broader comparison for an exploration of the evolutionary origins of gestural communication. Current estimates place the last common ancestor of the African apes and orang-utans at around 17 million yr. ago (Pozzi et al. 2014). However, and of more interest, orang-utans also occupy a very different socioecological niche from that of their African cousins. Communication, like other behaviors, is adapted to the niche of the species employing it (Cheney and Seyfarth 2018). The semisolitary and arboreal niche occupied by wild orang-utans provides a unique point of comparison for the communicative usage of their gestures, as compared to African apes. Chimpanzees and bonobos live in large multimale-multifemale groups of between 20 and $>200$ individuals, in a fission-fusion social structure (Aureli et al. 2008; Nishida 1968). While gorilla groups are typically much smaller, they also typically include multiple adult males and females, as well as immature individuals (Robbins and Robbins 2018). Play, sex, and display are among the most prolific contexts for gestural communication in wild or captive African apes (Fröhlich et al. 2016a; Genty and Zuberbühler 2014; Goodall 1986; Graham et al. 2017; Hobaiter et al. 2017; Plooij 1978; Schneider et al. 2012; Tomasello et al. 1997). In contrast, the most regular social partners in wild orangutans are mothers and their offspring (Mitani et al. 1991; van Schaik 1999). While siblings do interact, the long interbirth intervals of 6-8 yr. (Wich et al. 2004) limit sibling interactions to the first few years of life, with a large age difference. With no known long-distance audible gestures (cf. chimpanzee drumming: Arcadi et al. 1998, 2004), orang-utan signaling outside of mother-offspring is typically vocal (e.g., male long calls: Delgado et al. 2009; Mitani 1985). Recent studies have highlighted the importance of early socialization on African ape communication (Bard et al. 2014; Fröhlich et al. 2016a, 2017; Laporte and Zuberbühler 2011), but the impact of the social environment on the development of wild orang-utan gesture remains unknown.

Their ecological niche presents physical and cognitive challenges that also distinguish them from African apes. Their diet requires the acquisition of complex foodprocessing techniques (Galdikas 1988; Jaeggi et al. 2008; van Adrichem et al. 2006; Van Noordwijk and Van Schaik 2005; Wich et al. 2004) and their lifestyle is more arboreal (Thorpe and Crompton 2006). As a result, orang-utan hands and feet are employed simultaneously in locomotion more often than seen in African apes (chimpanzees and gorillas: Gebo 1992), perhaps limiting their availability for gesturing.

The socioecological environment of captive orang-utans differs strikingly from those in the wild. They are often housed socially with several adult individuals and offspring (Price and Stoinski 2007). As well as differences in the social partners and behavioral 
contexts available, the physical environment impacts signal selection and transmission (Hobaiter et al. 2017; Mitani et al. 1999). Captive habitats are limited in size, but also in form - with typically open enclosures that allow for longer lines of sight and more terrestrial behavior (Hebert and Bard 2000; Manduell et al. 2011). As a result, the expression of gestural communication in wild orang-utans may differ substantially from that recorded in captive groups (Cartmill 2008; Cartmill and Byrne 2010; Liebal et al. 2006). Given increasing anthropogenic pressures, many populations of wild primates are decreasing in numbers (Estrada et al. 2017). As all three species of orang-utan are considered Critically Endangered in the wild (Ancrenaz et al. 2016; Goossens et al., 2006; Nowak et al. 2017), there is also an urgent need for both research and conservation in their natural habitat.

Here, we provide an initial description of the gestural and vocal signal repertoire used in mother-offspring pairs of wild Southwest Bornean orang-utans. The largely arboreal lifestyle of wild orang-utans may impact both the expression of gestural forms, for example limb use, and the range of gesture types available in a particular interaction. We examine the selection of signals and their adjustment to recipient attention. We further explore the responsiveness of orang-utans to gestural communications and describe the range of goals for which gestures are employed between motheroffspring pairs.

\section{Methods}

We collected data during focal follows (Altmann 1974) of mothers and dependent offspring orang-utans within the Sabangau peat-swamp forest in Borneo, Indonesia, at the Borneo Nature Foundation (BNF) research site in conjunction with the Centre for International Co-operation in Management of Tropical Peatland (CIMTROP). The study site is a $500-\mathrm{km}^{2}$ protected area known as the Natural Laboratory of Peat Swamp Forest (NLPSF), which is managed by the University of Palangkaraya for the purposes of scientific research. A base camp is located at $2^{\circ} 19^{\prime} \mathrm{S}$ and $114^{\circ} 00^{\prime} \mathrm{E}$, $20 \mathrm{~km} \mathrm{SW}$ of Palangkaraya. Unlike most forests in Kalimantan, the Sabangau forest is not impacted by high levels of fragmentation, making it one of the largest continuous areas of peat-swamp forests left on the island (Morrogh-Bernard et al. 2003). This forest supports the largest population of orang-utans in the world at a density of two or three individuals per $\mathrm{km}^{2}$ (Husson et al. 2009; Morrogh-Bernard et al. 2003; Singleton et al. 2004; Wich et al. 2008).

\section{Subjects}

We followed 16 orang-utans over the course of the study; these included 7 motherdependent offspring pairs (Table I) and 2 older semiindependent offspring (Georgia, the maternal sibling of Gretel, and Isabella, the maternal sibling of Indy and Ima) that were occasionally encountered when interacting with the focal pairs. Following Rijksen (1978) and Morrogh-Bernard et al. (2002), we define age/sex groups as follows: infants (0-3 yr), juveniles (3-6.5 yr), adolescents (6.5-10 yr), adult females (females with young), unflanged males (adult), and flanged males (adult). Using these categories we included 7 adult females, 2 adolescents (both female), 6 juveniles (4 males and 2 
females), and 1 female infant. Six of the adult females had home ranges within the study site at the NLSPSF. We first encountered the seventh female and her offspring in spring of 2016, and believe that she was new to the area because of potential displacement from the nearby forest fires that occurred in September and October of 2015.

\section{Data Collection}

Standardized behavior and video data collection, based on the field data collection procedures by the Leakey Foundation Orang-utans Compared Workshop in San Anselmo, CA (Morrogh-Bernard et al. 2002), started in May 2014. We collected data in May 2014-July 2016, yielding a total of $681 \mathrm{~h}$ of recorded footage. We followed orang-utan pairs from nest to nest with a team of two or three observers for a minimum of 5 days per month if encountered and not lost. One or two people recorded primary behavioral, proximity, and vocalization data on both mother and offspring, while the remaining observer took video recordings. The majority of video data recorded were from orang-utans in an arboreal context. All ground observations were at a minimum distance of $10 \mathrm{M}$. minimum distance for arboreal observations was $5 \mathrm{~m}$, but 10-20 m was more typical. Where any orang-utan behavior appeared to be directed toward observers on approach or while moving to find an observation location, we stopped and/or increased our observation distance. Variation in observation distance and conditions impacts our ability to observe signals; for example, quieter vocalizations or subtle movements may be missed at greater distances. As a result, we employ ad libitum rather than continuous sampling of signals (Altmann 1974).

We recorded video and audio data using a Canon Powershot sx50 HS or Panasonic DMC FZ-1000 video camera and a Velbon up-400 monopod. The use of the built-in

Table I Focal orang-utan mother-offspring pairs followed

\begin{tabular}{llllll}
\hline Pair & Individual & Sex & Age class & Estimated birth month & Focal days (full) \\
\hline 1 & Feb & Female & Adult & Unknown & $14(10)$ \\
& Fio & Male & Juvenile & April 2010 & \\
2 & Gracia & Female & Adult & Unknown & $12(8)$ \\
& Gretel & Female & Juvenile & June 2010 & $11(8)$ \\
3 & Teresia & Female & Adult & Unknown & \\
& Trevor & Male & Juvenile & Nov. 2011 & \\
4 & Cleo & Female & Adult & Unknown \\
& Chuck & Male & Juvenile & July 2012 & $27(20)$ \\
5 & Indy & Female & Adult & Unknown & \\
& Icarus & Male & Juvenile & August 2012 & $13(10)$ \\
6 & Indah & Female & Adult & Unknown & \\
& Ima & Female & Infant & March 2014 & $1(0)$ \\
7 & Juno & Female & Adult & Unknown & \\
& Joy & Female & Juvenile & Unknown & \\
\hline
\end{tabular}

Identity, sex, and age of focal pairs followed in the Sabangau peat-swamp forest in Borneo, Indonesia 2014 2016. Number of focal days the pair were followed and, within this total, the number of these that were fullday focal events 
microphone on the video camera has significant limitations for the accurate collection of vocal signals, particularly within a noisy arboreal rainforest environment. As a result our vocal data are biased toward calls that were either louder or more acoustically distinct than the surrounding environment. Despite the limitations on the number and type of calls that could be coded, they still represented almost double the number of gestural signals recorded. (The coding of gestural signals typically excludes 20-40\% of potential cases where they do not meet the criteria for intentional use; see, e.g., Genty et al. 2009; Kersken et al. 2018.) As a result we felt that it was important to include the vocal data to highlight the importance of vocal signals in orang-utan communication, but we are cautious in our analysis and interpretation of them..

\section{Video Analysis}

Following Genty et al. (2009), we scanned videos clips for "potentially communicative" episodes before coding. Essentially this meant we isolated any circumstance in which at least two individuals were present and at least one individual was not occupied in a solitary activity such as self-grooming or sleep, resulting in $52 \mathrm{~h}$ of footage (hours of footage per individual: range $=0.33-15.94$, mean $=5.2 \pm \mathrm{SD} 4.5$; see Electronic Supplementary Material [ESM] Table SI). We coded all vocal and gestural signals used to initiate social interaction. Facial gestures were included here; however, facial expressions could not be coded consistently given visibility in the arboreal habitat. We coded facial expressions ad libitum where possible but they were not included in subsequent analyses. Vocal signals originate from the mouth or throat, and can be altered by the use of hands or foreign objects such as leaves (Hardus et al. 2009; van Schaik 2003). As specific calls used by orang-utans vary by location, known as "call cultures" (Wich et al. 2012), we classified calls using a condensed compiled ethogram adapted from BNF protocols and previous studies of captive and wild orang-utans (Table II). We defined gestural signals as discrete, mechanically ineffective physical movements of the body observed during periods of intentional communication (Cartmill and Byrne 2010; Hobaiter and Byrne 2011a). Discrete movements have a clear start and end point, typically distinguished by a pause or change in speed or direction of movement (Kita et al. 1997). We initially classified gestures following the repertoire described in Byrne et al. (2017; updated in Hobaiter and Byrne 2017), which included gestures previously seen in all four great apes in both captivity and in the wild. Example videos are available at http:/www.greatapedictionary.com Given the high level of facial muscle control found in orang-utans (Caeiro et al. 2013), we then extended the gesture list to include previously described orang-utan facial displays that were distinguished from facial expressions by the evidence for their intentional use (Cartmill 2008).

The exploration of intentional communication in either human or nonhuman primates is challenging, as it requires decoding a signaler's intention: an invisible cognitive state, from the signaler's observable behavior. The criteria for doing so were adapted from early explorations of language development in young children. Bates and colleagues (Bates et al. 1975) distinguished illocutory acts, in which an infant employed a conventionalized signal toward a recognizable goal, from perlocutory acts, in which a signal changed a recipient's behavior, but without any evidence that this effect was intended by the signaler. Tomasello and colleagues (Tomasello et al. 1985) 
Table II Orang-utan vocalizations recorded

\begin{tabular}{|c|c|}
\hline Vocalization name & Description \\
\hline Kiss squeak & A sharp kiss noise created on the inhale of air through trumpet-lips. ${ }^{1}$ \\
\hline Kiss squeak with hands & $\begin{array}{l}\text { Similar to a classic, mouth-only kiss squeak, but the noise is deepened } \\
\text { by the addition of a hand cupped around the signaler's mouth. }{ }^{1}\end{array}$ \\
\hline Kiss squeak with leaves & $\begin{array}{l}\text { Similar to a classic, mouth-only kiss squeak, but the noise is aided by } \\
\text { the holding of a leaf or leaves around the signaler's mouth. }{ }^{2}\end{array}$ \\
\hline Grumph & A low vocalization lasting $1-2 \mathrm{~s}$ made on the inhale. ${ }^{1}$ \\
\hline Kiss squeak + grumph & A classic kiss squeak followed immediately after by a single grumph. ${ }^{1}$ \\
\hline Gorkum & A classic kiss squeak followed by a series of multiple grumphs. ${ }^{1}$ \\
\hline Complex call & $\begin{array}{l}\text { A call created by the mixing and distorting of low guttural noises } \\
\text { including grumphs, rolling calls, kiss squeaks, and barks. }{ }^{1}\end{array}$ \\
\hline Grumble & $\begin{array}{l}\text { Created by low, quick, repeating exhalation noises, similar in sound } \\
\text { to a starting engine. }{ }^{3}\end{array}$ \\
\hline Long call & $\begin{array}{l}\text { Produced only by flanged and unflanged males; long calls often start } \\
\text { with grumbles, followed by pulses, and finish with bubbles. } \\
\text { The pulses are necessary to a long call, but grumbles and bubbles } \\
\text { do not always accompany them. }{ }^{1}\end{array}$ \\
\hline Lork & $\begin{array}{l}\text { Produced only by females and unflanged males; a lork is similar in } \\
\text { sound to a long call, but with noisier pulses and tail-offs that rise in pitch. }{ }^{1}\end{array}$ \\
\hline Squeak & A brief, high, and raspy vocalization often made in bouts. ${ }^{3}$ \\
\hline Soft hoot/whimper & $\begin{array}{l}\text { A call made up of two distinct noises. The primary soft hoot is a } \\
\text { high-pitched noise created on the exhale that is then drawn } \\
\text { into long, often softer whimpers that are interjected with } \\
\text { soft hoots. } 1\end{array}$ \\
\hline Cry/scream & $\begin{array}{l}\text { Higher in pitch and intensity than a soft hoot/whimper; } \\
\text { screams are made alongside choked air noises on the inhale. }{ }^{1}\end{array}$ \\
\hline Frustration scream & $\begin{array}{l}\text { Similar in sound to a soft hoot-whimper, but punctuated by } \\
\text { short gaps in the rising wails. }{ }^{1}\end{array}$ \\
\hline Throatscrape & A soft noise resembling a croak. ${ }^{4}$ \\
\hline Nestsmack & $\begin{array}{l}\text { A soft smack noise potentially created by moving the } \\
\text { tongue against the palate and can be made in either a } \\
\text { low or high frequency. }{ }^{4}\end{array}$ \\
\hline Raspberry & $\begin{array}{l}\text { A voiceless vocalization in which a faint spluttering noise } \\
\text { is created on the exhalate. }{ }^{1}\end{array}$ \\
\hline Other & Unidentified call, described in notes. \\
\hline
\end{tabular}

Call type, descriptions, and first instance recorded. ${ }^{1}$ Mackinnon (1974); ${ }^{2}$ Peters (2001); ${ }^{3}$ Rijksen (1978); ${ }^{4}$ van Schaik et al. (2006). In our data from the Sabangau peat-swamp forest in Borneo, Indonesia (2014-2016) coding of vocal signals from video files means that our record of vocal signals is biased toward calls that were either louder or more distinctive than the surrounding acoustic environment

adapted Bates' criteria for use with nonhuman apes, and subsequent studies of intentional communication in nonhuman animals have employed similar criteria.

We define intentional communication as including at least one of three criteria: 1) The signaler orients its body and gaze toward the recipient (Call and Tomasello 2007; Cartmill and Byrne 2010); 2) the signaler waits for a response from the recipient followed by repeating the gesture if the desired response is not obtained (Call and 
Tomasello 2007; Leavens et al. 2005a; Tomasello et al. 1994); and 3) in the absence of a response that in other cases is satisfactory, the signaler employs persistence toward a goal, such as modifying the gesture depending on recipient response, or lack thereof, or using the gesture in conjunction with other gestures or communicative behavior (Cartmill and Byrne 2007; Leavens et al. 2005; Tomasello et al. 1994). We require each case of potential gesture use to meet at least one of these criteria to be considered a case of intentional gesture.

Coding of gaze direction is challenging in a natural setting, particularly from arboreal subjects. Following Hobaiter and Byrne (2011a, 2011b), we included an individual as directing its gaze toward a recipient where gaze was visible, or where head movements indicated that it was tracking recipient movements (in the way, for example, that gaze direction can be inferred while standing behind someone watching a tennis match, where the person's head movements track the ball's). Further details of the coding are provided in the text that follows.

Gestural signals are typically categorized by modality into three groups corresponding to silent-visual, audible, or contact (e.g., Hobaiter and Byrne 2011a). All gestures include a visual component, audible gestures always included an audible component as a result of the action (cf. silent-visual gestures that occasionally make "accidental" contact with a surface, such as an arm "Swing" gesture that contacts leaves), and contact gestures always make physical contact with the recipient and may also include an audible component. After video coding, but before analysis, we collapsed the categories of modality into visual and tactile. Visual included both silent and audible visible gestures. We combined these because reliably discriminating audible from silent-visual gestures was challenging in the arboreal habitat, with leaf and branch noises accompanying most movements. Although some gestures did appear to employ sound purposefully, such as "Stomp" and "Shake object," we saw these in very low frequencies and therefore combined them with all other visual gestures.

For both the signaler and recipient we coded individual identity and age, the behavioral context immediately before and after signaling (Affiliating, Agonistic, Display, Feeding-individual, Feeding-food sharing, Grooming, Nesting, Nursing, Play-social, Play-solitary, Resting, Sex, Moving, Traveling, Other, Unknown; see Table SII for definitions), the estimated distance between the signaler and recipient $(<1 \mathrm{~m}, 1-2 \mathrm{~m}, 2-3 \mathrm{~m}, 3-5 \mathrm{~m}, 5-10 \mathrm{~m},>10 \mathrm{~m}$; distances estimated using body size as a point of reference; Cant 1992; Oishi et al. 2009). We recorded the state of the recipient's visual attention at the time that the signal was initiated as attending (recipient had eye contact with the signaler or showed tracking of the signaler's behavior through head or body movements); head in direction (recipient located in front of the signaler with the head in an arc of up to $45^{\circ}$ in either side of the direction the signaler is facing); partial view (the recipient is in the signaler's peripheral view, with the head at $45-90^{\circ}$ to either side); out of sight (recipient is not in a position to see any physical movement made by the signaler); out of sight but in body contact (as out of sight, but recipient is in physical contact with the signaler). Signal combinations may be produced as a planned combination of signals, or because of the addition of another signal after the failure of an earlier signal (Genty and Byrne 2010; Hobaiter and Byrne 2011b; Liebal et al. 2004b). We followed Hobaiter and Byrne (2011b) in distinguishing these two types of signal combination. Sequences are two or more signals that are overlapping or 
Table III Results of interobserver and intraobserver reliability testing, by coding category

\begin{tabular}{|c|c|c|c|c|}
\hline \multirow[t]{2}{*}{ Coding category } & \multicolumn{2}{|c|}{ Interobserver results } & \multicolumn{2}{|c|}{ Intraobserver results } \\
\hline & K & $\%$ Agreement & K & $\%$ Agreement \\
\hline Intentionality & 0.78 & 91.5 & 0.83 & 90.7 \\
\hline Attention of recipient & 0.70 & 86.4 & 0.73 & 91.0 \\
\hline Gaze before signal & 0.62 & 78.2 & 0.74 & 85.5 \\
\hline Gaze during signal & 0.65 & 79.7 & 0.73 & 84.8 \\
\hline Gesture type & 0.86 & 94.8 & 0.84 & 91.3 \\
\hline Facial expression & 0.68 & 81.2 & 0.73 & 82.2 \\
\hline Vocalization type & 0.89 & 91.4 & 0.92 & 94.9 \\
\hline Goal of signaller & 0.69 & 87.2 & 0.69 & 88.5 \\
\hline Signaler persistence & 0.49 & 75.7 & 0.71 & 83.1 \\
\hline Signaler context & 0.68 & 77.9 & 0.75 & 80.5 \\
\hline Recipient response & 0.75 & 88.9 & 0.70 & 87.3 \\
\hline
\end{tabular}

Interobserver reliability was assessed on $10 \%$ of the data, and intraobserver reliability was assessed on an additional $7.5 \%$ of the data. We report both the $\mathrm{k}$ value and the $\%$ agreement across coding categories

separated by $<1 \mathrm{~s}$. Bouts are two or more individual signals or sequences of signals that are produced with $\geq 1$ s of response waiting between them.

\section{Interobserver Reliability}

We code video data across ape gestural studies employing the same methodology and coding protocol independently of the hypotheses tested or study population. AK and $\mathrm{EH}$ were trained by experienced gesture coder $\mathrm{CH}$, and each then coded $55 \%$ of all video footage. We assessed reliability both between and within coders. We used an overlapping $10 \%$ of coded footage to assess interobserver reliability. We evaluated intraobserver reliability by coding a separate $7.5 \%$ of the total video footage twice, but $\geq 72 \mathrm{~h}$ apart. We selected videos for reliability testing using a random number generator, and measured the degree of concordance for specific coding categories between the ratings using both percentage agreement and Cohen's K (Altman 1991). The results of the inter- and intraobserver reliability testing showed 76-95\% overlap and "moderate" to "very good" agreement for 10 of the 11 variables (Table III), suggesting that coefficients exceed chance for coded behavior (Bakeman and Gottman 1997; McHugh 2012). The interrater agreement on signaler persistence was $76 \%$ but achieved only a "weak" degree of agreement $\mathrm{k}$ score $(0.49)$.

\section{Analysis}

In describing the repertoire of wild chimpanzees, Hobaiter and Byrne (2011a) required at least two instances of gesture use by an individual to include it in an individual repertoire, and use by at least two individuals to include it in possible species repertoires. However, as our dataset was relatively small and research has indicated that repertoire size is closely correlated to the quantity of data recorded in smaller dataset 
(Hobaiter and Byrne 2011a), we describe all potential gesture types used and provide the number of instances of gesture use. We calculated the number of gesture types identified relative to the number of gesture instances (an individual example of gesture use) coded for the total dataset, and individually for both the adult and offspring datasets. We graphed these for visual inspection to assess whether the repertoires reached asymptote. To address any effect of pseudoreplication from the use of ad libitum sampling, we converted data to means for each individual before analyses.

In analyses of signal choice we excluded any signals where the recipient's attention state was unclear, as well as any signals apparently directed toward observers in order to restrict our analyses to signal use between orang-utans. We conducted analyses of signal choice with recipient attention state by fitting generalized linear mixed effect models (GLMM) using a binomial error distribution and logarithmic link function in RStudio 1.0.136 running $\mathrm{R}$ version 3.3.1 (2016-06-21). We fitted models using the lme4 package for $\mathrm{R}$. We included only single signals, or the first signal in a rapid sequence (signals separated by $1 \mathrm{~s}$ or less; following Hobaiter and Byrne 2011b), in analyses of attention state, and excluded signals from an individual with fewer than five communicative interactions (communications). The GLMM included only intentional gestures and used gesture modality as the response to recipient attention. In addition, we included the social relationship (mother-infant, other; typically mother-infant), signaler age class (adult, immature), and signaler location (ground, tree) in the model as control effects. The GLMM included signaler identity $(N=12)$, recipient identity $(N=13)$, signaler context before communication $(N=16$ levels; see Table SII), and recipient context before communication $(N=16$ levels; see Table SII) as random effects. These factors have the potential to influence the choice of intentional signal; however, we have insufficient data to fully explore these in this analysis and the observations recorded represent a small and random sample of the possible levels in each factor. We include them as random effects in order to take into account their impact. We report the influence of recipient attentional state and the three control factors (Bolker et al. 2008). We applied a likelihood ratio test using $\chi^{2}$ tests of independence to assess the potential correlation between the attention state of the recipient and the intentionality and modality of the following communicative signal.

To further quantify the use of gesture modality with recipient attention, we calculated the variation in usage (following Hobaiter and Byrne 2011a). First, we calculated the proportion of signal usage by modality across the complete corpus by individual. Next, we calculated the percentage deviation from this baseline use for each state of recipient attention with the following formula: Deviation $=(\beta / \alpha-1) * 100$, where $\beta=$ portion of signals within each attention state and $\alpha=$ portion of signals in the overall corpus. We then analyzed the resulting deviations, indicative of adjustments made by the signaler based on recipient attention state, using planned $t$-tests, and reported them with the mean \pm standard deviation.

We did not have sufficient cases of successful gesture use per individual to explore whether specific goals were associated with each gesture type. However, as research has shown that individual signaler identity did not impact signal meaning (Graham et al. 2018; Hobaiter and Byrne 2014), we present a preliminary investigation here in which gesture use was combined across signalers. After a gesture was employed, the reaction that caused the signaler to stop signaling was deemed to be the apparently satisfactory outcome, or goal, of the gesture. 


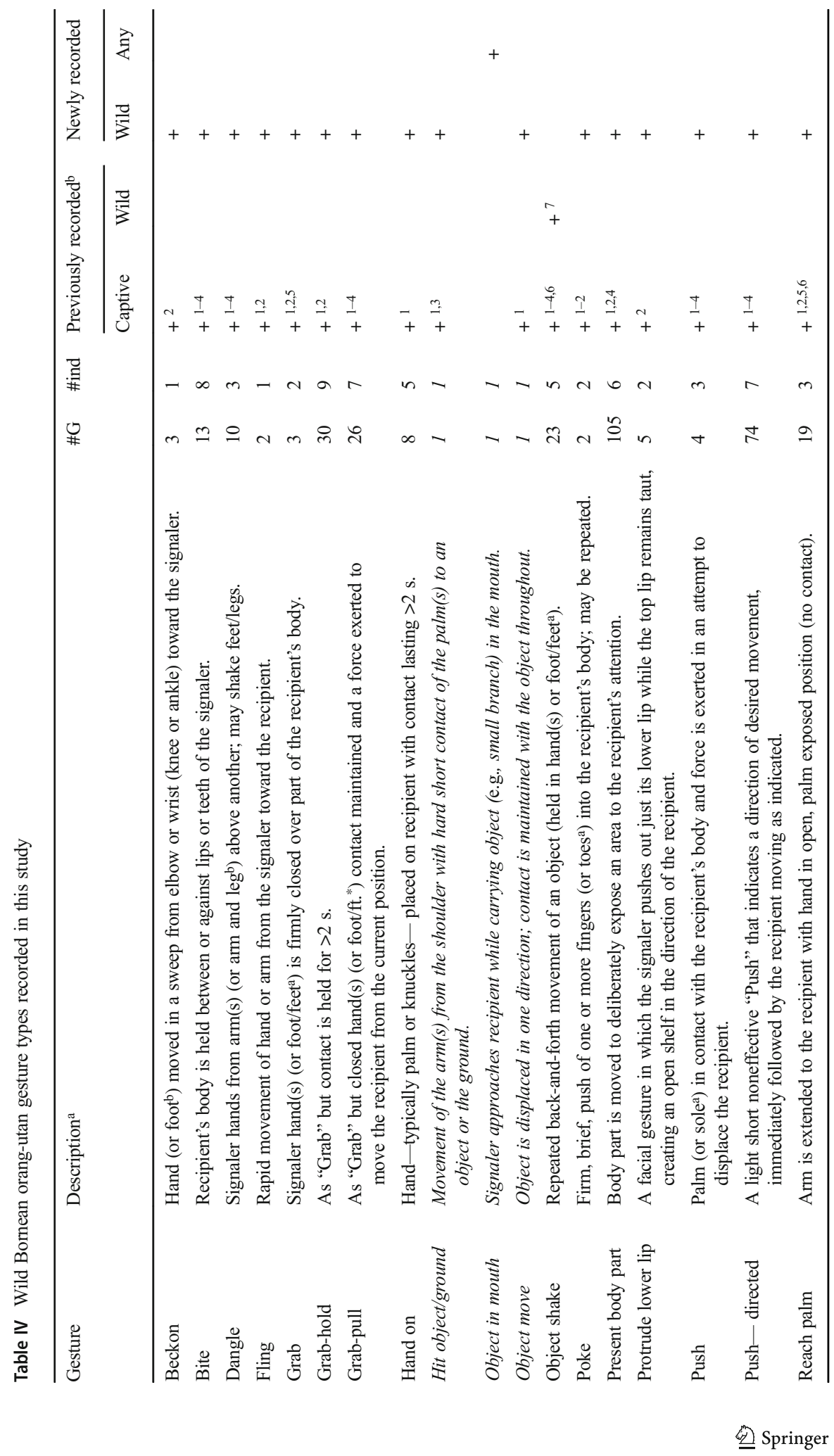




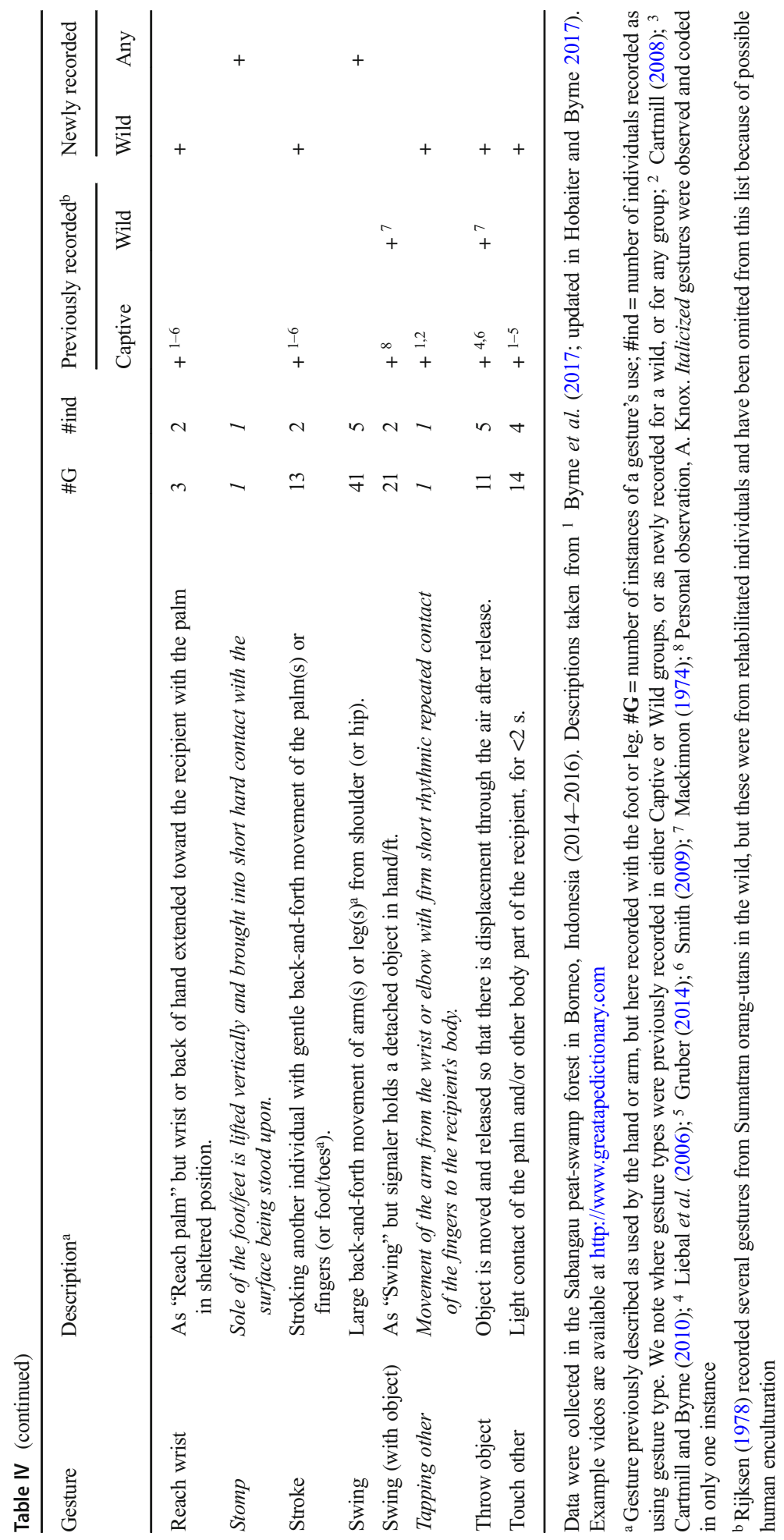




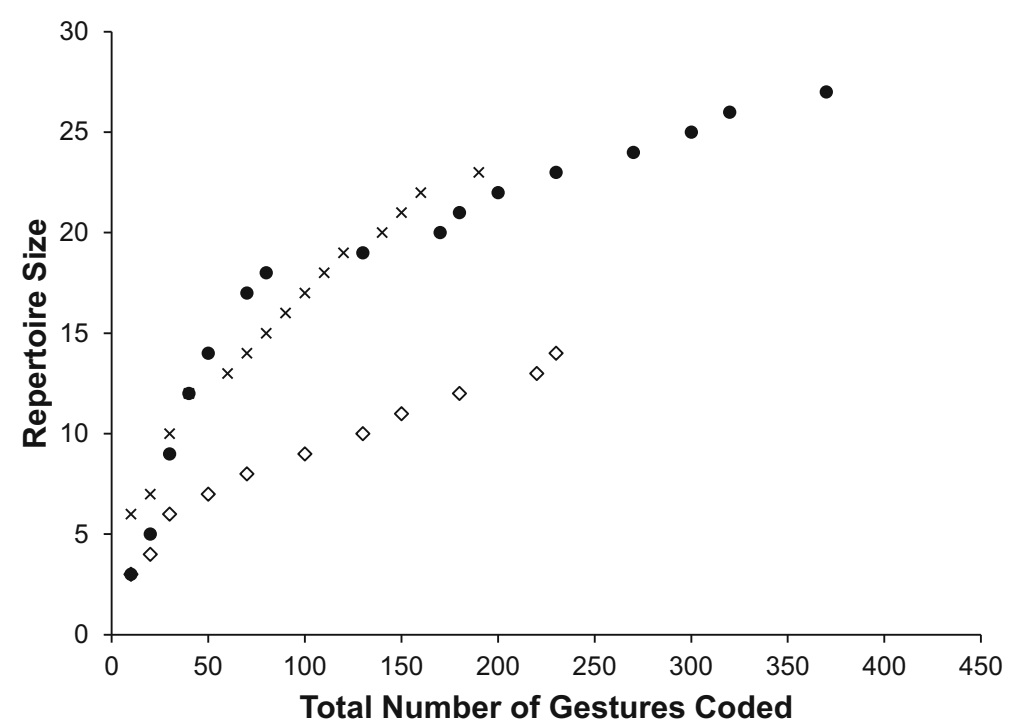

Fig. 1 The total number of intentional gesture types in the repertoire (solid circles) for all observed Bornean orang-utans ( $N=14$ individual) is plotted against the cumulative number of coded gestures. Data were collected in the Sabangau peat-swamp forest in Borneo, Indonesia (2014-2016). The graph also includes the same plot with the data separated for immature orang-utans $(N=8$; crosses $)$ and adults $(N=6$; hollow diamonds).

Data Availability The datasets analysed during the current study are available in the figshare repository, https://figshare.com/articles/DATA_Orang-utan_Signalling/8132159.

\section{Ethical Note}

This was an observational study that did not contain any interventions. All research adhered to the ethical ASAB/ABS Guidelines for the Use of Animals in Research and followed the IPS Code of Best Practices for Field Primatology. Permission for the study was granted by RISTEK. The authors declare they have no conflict of interest.

\section{Results}

Video coding yielded 1299 communicative signals: 858 vocal signals and 441 gestural signals. The majority of signals in our dataset were produced while in the canopy (signaler location canopy: $N=1267$, ground: $N=17$, unclear $N=15$ ). Where a recipient could be identified, signaling was typically between mothers and infants $(N=412)$. Signaling between other individuals in our dataset (e.g., siblings, unrelated individuals) was relatively rare $(N=19$; see Table SIII). Signals apparently directed toward human observers $(N=295)$, unknown recipients $(N=530)$, and other species $(N=41)$ were excluded from all further analyses. 
Table V The goals for which gestures were employed

\begin{tabular}{|c|c|c|}
\hline Goal & Definition & $\begin{array}{l}\text { Gesture } \\
\%(N)\end{array}$ \\
\hline "Acquire Object" & $\begin{array}{l}\text { The signaler stops gesturing when the recipient gives the } \\
\text { signaler an object (e.g., food, etc.). }\end{array}$ & $9(38)$ \\
\hline "Climb on me" & $\begin{array}{l}\text { The signaler stops gesturing when the recipient } \\
\text { climbs on the signaler's body. }{ }^{1}\end{array}$ & $31(138)$ \\
\hline "Climb on you" & $\begin{array}{l}\text { The signaler stops gesturing when the recipient permits the } \\
\text { signaler to climb on them. }{ }^{\text {a }}\end{array}$ & $0.2(1)$ \\
\hline "Climb over" & $\begin{array}{l}\text { The signaler stops gesturing when the recipient crosses over the } \\
\text { area that the signaler is currently occupying. }\end{array}$ & $5(23)$ \\
\hline "Move away" & $\begin{array}{l}\text { The signaler stops gesturing when the recipient moves away } \\
\text { from the signaler. }\end{array}$ & $2(11)$ \\
\hline $\begin{array}{l}\text { "Play change: decrease } \\
\text { intensity" }\end{array}$ & $\begin{array}{l}\text { The signaler stops gesturing when the recipient changes the } \\
\text { type of play from contact to chasing play. }{ }^{\mathrm{a}}\end{array}$ & $0.2(1)$ \\
\hline "Resume play" & $\begin{array}{l}\text { The signaler stops gesturing when the recipient resumes } \\
\text { playing after a pause in the activity. }{ }^{\text {a }}\end{array}$ & $3(15)$ \\
\hline "Stop that" & $\begin{array}{l}\text { The signaler stops gesturing when the recipient either ceases behavior } \\
\text { previously directed toward the signaler or changes its behavior to } \\
\text { direct it toward another individual. }^{\text {a }}\end{array}$ & $2(10)$ \\
\hline "Unknown" & $\begin{array}{l}\text { Intentional gesture fails to elicit a response, and/or unable to } \\
\text { attribute the intended purpose. }\end{array}$ & $46(204)$ \\
\hline
\end{tabular}

Goals were defined using the Apparently Satisfactory Outcome (ASO) method and are provided along with the percentage frequencies with which gestures were employed toward a particular ASO

a Definitions follow Hobaiter and Byrne (2014). We provide both the percentage of total gesture cases employed toward a specific goal and the number of gesture cases. Data were collected in the Sabangau peat-swamp forest in Borneo, Indonesia (2014-2016)

We found no difference in the proportion of signal types used between adult $(N=7$; mean proportion of gestural signals $=32.4 \% \pm \mathrm{SD} 22.5$, range: $0-58.9$ ) and juvenile signalers $(N=6$; mean proportion of gestural signals $=24.3 \% \pm$ SD 12.8, range: $13.3-$ 49.3; $t$-test, $t=0.778$; df $=11, P=0.453$ ). There were too few infant or adolescent signalers to compare the use of signal types in these age groups.

\section{Signal Choice in Response to Recipient Visual Attention}

Orang-utans also varied their selection of gesture modality (visual or tactile) with the recipient's visual attention $\left(N=335\right.$ gestures; GLMM: $\chi^{2}(4, N=335)=24.56$, $P<0.001$; see Tables SIV and SV for full model information). The distribution of residuals from the full model was normal, supporting the model fit (Fig. S1). Orangutans increased their use of visual gestures when the recipient showed visual attention, and decreased it when the recipient was out of sight (attending: $N=10$ mean $=47.3 \pm$ SD 50.1; not attending $N=10$, mean $=-57.6 \pm$ SD 39.3; $t=5.21$, $\mathrm{df}=17.03, P<0.001$ ). In contrast, they decreased their use of tactile gestures when the recipient showed visual attention, and increased it when the recipient was out of sight (attending: $N=10$ mean $=$ $-23.2 \pm$ SD 29.9; not attending $N=10$ mean $=35.9 \pm$ SD 33.5; $t=-4.16, \mathrm{df}=17.77$, $P<0.001$ ). There was an effect of signaler location (ground, tree) on signal choice (Table SIV); however, only 17 of the 335 gestures were produced while on the ground (all in a feeding context) so further statistical exploration was not possible at this time. 


\section{Vocal Communication}

Our identification of vocal signals was limited to those that could be discriminated within our video data, and likely underrepresents signal frequency, and biases signal types to those that are more distinct within the surrounding acoustic environment. Of the 855 vocalizations recorded we identified 11 types, all of which had been previously recorded in Bornean orang-utans (Table II). Four call types were used across age groups: "Grumph" $(N=3$ recorded instances of use), "Kiss squeak" $(N=321)$, "Kiss squeak + hands" ( $N=29)$, and "Raspberry" $(N=14)$. "Complex calls" $(N=5)$, "Gorkums" $(N=$ $52)$, and "Kiss-squeak grumphs" $(N=266)$ were recorded only from adult females; and "Cries and screams" $(N=5)$, "Frustration screams" $(N=6)$, "Grunts" $(N=2)$, and "Soft hoot whimpers" $(N=147)$, were recorded only from immature orang-utans.

\section{Gestural Communication}

We recorded 441 instances of gestural signals that met criteria for intentional use. Gestures were produced individually $(N=131)$, and in sequence with other gestures ( $N=30$ instances; $N=15$ sequences). Twenty-six distinct gesture types were provisionally identified; however, five of these were recorded on only a single occasion, and so do not, so far, meet the criteria for inclusion in individual or species repertoires (Table IV). When plotted cumulatively against the total number of gesture tokens coded, neither the total, nor the individual adult or offspring repertoires reached asymptote (Fig. 1), suggesting that further gesture types remain to be identified. Fourteen gesture types were used by adult female orang-utans, and 22 gesture types by their immature offspring. The gestures "Push," "Protrude lower lip," "Beckon," and "Tap" were observed being used only by the adult females; and the gestures: "Swing arm," "Swing leg," "Swing object," "Hand on," "Dangle," "Reach palm," "Throw object," "Hit object/ground," "Fling," "Stomp," "Object move," and "Object in mouth" were observed being used only by immature individuals. Signalers were more likely to gesture when the recipient was in close proximity: $84 \%$ of all gestures were executed when the recipient was $<1 \mathrm{~m}$ from the signaler. Gestures carried out when the recipient was 2 or more $\mathrm{m}$ away were exclusively silent-visual "Present" gestures.

Adults deployed a similar proportion of tactile gestures $(N=6$; mean proportion $=$ $54.3 \% \pm$ SD 23.9, range: 33.3-85.7) as visual (audible or silent: mean proportion $=$ $45.7 \% \pm$ SD 23.9, range: $14.3-66.7$; paired $t$-test: $t=0.440, \mathrm{df}=5, \mathrm{SE}=0.195, P=$ $0.679)$, whereas juveniles employed fewer tactile gestures $(N=6$; mean proportion: $13.9 \% \pm$ SD 16.3, range: $0-37.7$ ) than visual (audible or silent: mean proportion $=$ $86.1 \% \pm$ SD 16.3, range: $62.3-100$; paired $t$-test: $t=5.44, \mathrm{df}=5, \mathrm{SE}=0.133, P=$ $0.003)$. There were too few infant or adolescent signalers to compare the use of modalities in these age groups.

\section{Gesture-Vocal Combinations}

Our sample size of signal combinations is small, and interrater reliability testing indicated that there was only weak consensus on the coding of persistence, which distinguishes sequences and bouts. As a result we provide only a basic description of signal combination use. Gesture-vocal combinations within a sequence $(<1 \mathrm{~s}$ 
separation between signals or overlapping) were rare $(N=15)$, and typically involved Kiss-squeak vocalizations $(N=14)$ together with a range of gesture types ("Objects shake," "Swing with object," arm "Swing," "Dangle," and "Throw object"). Individual vocalizations or vocal-only sequences were employed in the same communicative bouts (individual signals or sequences separated by $\geq 1$ s of response waiting) as gestures or gesture-only sequences $(N=13)$ but here the signals from the two modalities were produced in succession, separated by periods of response waiting.

\section{Limb Use in Gestural Communication}

Many gesture forms can be produced with either the hand/arm or foot/leg, for example Reach, Swing. We compared the relative frequency of hand/arm and foot/leg forms of these gestures produced by orang-utans with those in a dataset of chimpanzee communication $(N=4221$ instances of gesture use). Thirty of the chimpanzee gesture types could be produced with either the hand/arm or foot/leg; within these gesture types there was a strong bias toward hand/arm foot production in chimpanzees $(N=2239$ gesture instances, $N=2185 \mathrm{hand} / \mathrm{arm}, N=54 \mathrm{leg} / \mathrm{ft}$; binomial test: $P<0.0001)$. There was a similar bias toward production of gesture types with the hand/arm in orang-utan gestures ( $N=18$ gesture types, $N=258$ gesture instances, $N=214$ hand/arm, $N=34$ leg/ft.; binomial test: $P<0.001$ ); however, orang-utans were more likely than chimpanzees to use the leg/ft. forms (Chi-square: $\chi^{2}=83.5, P<0.001$ ) and also produced gesture forms that involved use of both a hand/arm and a leg/ft. at the same time $(N=10)$.

\section{Responsiveness to Gestural Requests}

Orang-utans were generally very responsive to gestural requests; $80 \%(N=205 / 255)$ of communications including intentional gestures were successful in achieving a satisfactory behavioral response. There was relatively little variation in responsiveness between mother-offspring pairs (pairs with three or more communications, $N=7$; mean $=79 \%$ \pm SD 9; range: 67-91\%). Where gestural communications were successful, orang-utans frequently responded before the end of the final signal-overlapping response (pairs with three or more communications, $N=6$; mean $=35 \% \pm \mathrm{SD} 26$ ) - or within $1 \mathrm{~s}$ of the final signal (pairs with three or more communications, $N=6$; mean $=55 \% \pm \mathrm{SD} 25$ ), although this varied strikingly between mother-offspring pairs (overlapping responses: range: 0-67\%; within $1 \mathrm{~s}$ responses: range: $20-83 \%$ ).

\section{Goals Associated with Gestural Communication}

Orang-utans used $N=237$ gestures in $N=205$ communications to successfully achieve at least one of eight goals: Acquire object; Climb on me; Climb on you; Climb over; Move away; Play change: decrease intensity; Resume play; Stop that (Table V). Twelve gesture types were used successfully on three or more occasions (11 of these 12 were used by more than one individual successfully, range: $1-8$ signalers per gesture types, mean $=3.8$ \pm SD 2.1). These gestures were used to achieve a mean $2.8 \pm$ SD 1.4 goals (range 1-6 successful goals per gesture type); however 4 of the 12 gestures were used toward one or more play goal. If we consider only nonplay goals, gestures were used to achieve a mean $1.9 \pm \mathrm{SD} 0.9$ goals (range $1-4$ successful goals per gesture type). 


\section{Discussion}

Twenty-one gesture types and 11 call types were identified in the signaling of wild mother and offspring orang-utans in the Sabangau peat-swamp forest in Borneo. All call types had previously been identified, but our ability to discriminate call types was limited by our use of video data and by our focus on mother-offspring communication, and as a result we likely underestimate the call repertoire. In addition to the 21 gestures included in the repertoire, an additional five gesture types were observed on a single occasion. Three of these have been described in the gestural repertoires of captive populations, and the two gesture types new to descriptions of orang-utan gesture use have been described in other ape repertoires (see Table IV and Byrne et al. 2017). Our criteria for inclusion as a case of gesture are strict, and can lead to the exclusion of 20 $40 \%$ of potential cases (e.g., Genty et al. 2009; Kersken et al. 2018). Given our small dataset we suggest that these gesture types, and others that remained unobserved, would likely meet criteria for inclusion with additional observations, also extending the total gestural repertoire size. Of the gesture types observed, 3 were previously unreported in orang-utans, and 20 were previously unrecorded in wild orang-utans. Eleven of these gesture types were employed with a higher degree of physical versatility than in previous descriptions, for example, the same action being used with the foot or leg, where previously only the hand or arm had been described (e.g., Byrne et al. 2017). Combinations of gestural and vocal signals occurred as both simultaneous and sequential combinations, but both forms were rare.

Orang-utan signalers were very responsive to gestural requests, with ca. $90 \%$ of all successful communications occurring with either an overlapping or immediate $(<1 \mathrm{~s})$ response. This fluid "style" of communication more closely resembles that described for bonobos (Fröhlich et al. 2016c), as compared to chimpanzees, where delayed responses $(\geq 2 \mathrm{~s})$ were observed as frequently as more responsive behavior (Fröhlich et al. 2016c). Previous studies from both captive and wild groups of apes suggest that apes' use of gesture is impacted by their early social experience (e.g., Bard et al. 2014; Fröhlich et al. 2016a, b; 2017; Hobaiter and Byrne 2011b; Schneider et al. 2012; Tomasello et al. 1989). The extended period of dependency, necessary for orang-utans to occupy a cognitively demanding ecological niche (Galdikas 1988; Jaeggi et al. 2008; van Adrichem et al. 2006; Van Noordwijk and Van Schaik 2005; Wich et al. 2004), as well as their very restricted number of social partners as compared to African apes (Mitani et al. 1991; van Schaik 1999), likely influence their understanding of the communicative intentions of their partners, perhaps increasing their responsiveness.

Orang-utans are highly flexible in their use of limbs in order to exploit their arboreal niche (Manduell et al. 2011; Thorpe and Crompton 2005, 2006). In comparison with chimpanzee gesturing, we found that orang-utans were more likely to employ leg/ft. forms of gestures that had both a hand/arm and leg/ft. variant, and that orang-utans were more likely to use hand/ft. or leg/arm combinations in gesture forms that involved the use of two or more limbs. As a result, where only the limb use varied from existing descriptions of gesture types in other apes, we were conservative in listing them as variants of the same gesture type, rather than as novel gesture types. While we provide an initial description of gesture types employed by wild orang-utans, our analyses show no asymptote in the repertoire, strongly suggesting that additional gesture types remain to be described. Similarly, while we found low levels of overlap in the gestural 
repertoires of mothers and their offspring (10 of 26 gesture types), no age-class repertoire reached asymptote, and so further study is needed to properly describe any variation in the use of different gesture types within the repertoire across development. We found that the proportion of tactile to visual gesture types varied between adult and juvenile signalers, with a bias toward visual gestural signal use in younger signalers. Previous studies have found either similar proportions of use (Schneider et al. 2012), or a bias toward the use of tactile gestures in infant apes (Fröhlich et al. 2016a); however, the use of tactile signals decreased with increasing independence from the mother (Fröhlich et al. 2016b; Plooij 1978), and so the variation in our data may reflect the comparison of juvenile, rather than infant, to adult signalers. Furthermore, as our data were collected across a wide range of behavioral contexts, and specific gesture types are associated with specific signaler goals (Cartmill and Byrne 2010; Hobaiter and Byrne 2014), the variation in signal selection may reflect a variation in adult and juvenile signaler goals, rather than a specific shift in modality of gesturing with age. The semisolitary social environment of wild orang-utans not only limits the frequency of social interactions in general, but particularly limits the frequency of contexts, such as play or sexual solicitation, that are among the most prolific for gesture use in wild African apes and captive orang-utans (Cartmill 2008; Fröhlich et al. 2016a; Genty and Zuberbühler 2014; Goodall 1986; Graham et al. 2017; Hobaiter et al. 2017; Plooij 1978; Schneider et al. 2012; Tomasello et al. 1997). As a result, gestures employed only rarely and gestures associated with goals typically expressed in play or sexual contexts are likely absent from our data.

Supporting previous findings from captive groups (Cartmill and Byrne 2007; Liebal et al. 2004a; Poss et al. 2006; Waller et al. 2015) and across other ape species (e.g., Hobaiter and Byrne 2011a; Leavens et al. 2005a; Tomasello et al. 1994), orang-utan signalers vary their production of intentional gestures depending on the visual attention of their audience, adjusting the modality of their signal (visual or tactile) to match the visual attention of their recipient (attending or not attending). These findings suggest that apes understand the physical basis of their gestural signals and that the gaze of the recipient is important in successfully deploying a visual gesture. Adjusting signaler behavior to match recipients' visual attention can be achieved either by moving position so that the visual gesture is produced within the recipient's line of sight, or by selecting a gesture type that includes information encoded in the auditory or tactile modalities. While evidence for both methods has been found in captive signalers (Liebal et al. 2004a, 2004b), we very rarely observed wild orang-utan signalers adjusting the position from which they signaled, instead finding that they employed tactile gestures toward out-of-sight recipients. This bias may reflect the constraints of their arboreal niche, in which repositioning may be more costly than in more open terrestrial habitat typical of captive environments (Hebert and Bard 2000; Manduell et al. 2011).

While a much larger dataset is needed to systematically define the gestural meanings of specific gesture types, we could describe the goals for which the orang-utans used their gestures and the relative flexibility of gesture types. Gestures were employed to achieve eight distinct goals, including six positive requests (Acquire object; Climb on me; Climb on you; Climb over; Play change; Play continue) and two negations (Move away; Stop behavior). As found in chimpanzees and bonobos (Graham et al. 2018; Hobaiter and Byrne 2014), gestures were employed flexibly toward multiple goals, but 
the majority of gesture types were used to achieve at least one play-related goal; thus, flexibility decreased (to an average of two goals per gesture type) when play data were removed. These findings suggest that orang-utans also show means-ends dissociation in their gesturing, with individual gesture types used to achieve several distinct goals and several gestures employed to express an individual goal. While there is increasing evidence for signaler control over and intentional use of some ape vocalizations (Crockford et al. 2012, 2015, 2017; Schel et al. 2013a, 2013b), these tend to be one or two signals each tightly associated with specific information, such as danger or food. Ape gestural communication remains distinct, outside of human language, in the scope and flexibility of the gestural signals and their meanings.

The exploration of gestural communication in wild orang-utans is not straightforward. Orang-utans experience fewer social interactions than other nonhuman ape species (Delgado Jr. and van Schaik 2000; Galdikas 1985; van Schaik 1999). In combination with their arboreal lifestyle in a dense, high-canopy habitat (Thorpe and Crompton 2006), this makes video data collection of communicative signals particularly challenging: almost $700 \mathrm{~h}$ of video footage were required to provide even a modest first description. Nevertheless, within this we could provide confirmation of gesture types never previously recorded for orang-utans, and not previously recorded in wild populations, and that some aspects of their gesturing-for example, an apparent difference in the diversity of limb use - may reflect specific adaptations to their natural habitat. Given the rapid decline in orang-utan populations across all species (Davis et al. 2013; Goosens et al. 2006; Meijaard et al. 2010, 2011; Nowak et al. 2017), and the occurrence of cultural variation between groups in their signaling (Lamiera et al. 2013), further research on understudied areas of their behavior, such as their gestural communication, is urgently needed..

Acknowledgments We would like to thank all our sponsors: the late Dr. Suwido Limin, Director of CIMTROP, University of Palangkaraya, for supporting our research in the Natural Laboratory (LAHG) and to the Ministry of Research, Technology, and Higher Education (RISTEK) for granting permission to undertake this research. We thank our financial supporters: US Fish and Wildlife Service Great Apes Conservation Fund, ARCUS, The Kronendak Foundation, and the Borneo Nature Foundation (BNF). We thank the editor, editor-in-chief, and two anonymous reviewers for their helpful comments on our manuscript. Special thanks to all our field assistants, especially Twentinoloso, Unyil, Aman, Jali, Adul, and Rebecca, all of whom helped collect field data for this project.

Author Contributions JM HMB conceived and designed the study. JM and AA conducted fieldwork. AK JM EH CH FJFV HMB coded behaviour and analyzed the data. AK JM EH CH FJFV HMB wrote the manuscript.

Open Access This article is distributed under the terms of the Creative Commons Attribution 4.0 International License (http://creativecommons.org/licenses/by/4.0/), which permits unrestricted use, distribution, and reproduction in any medium, provided you give appropriate credit to the original author(s) and the source, provide a link to the Creative Commons license, and indicate if changes were made.

\section{References}

Altman, D. G. (1991). Practical statistics for medical research. Boca Raton: CRC Press.

Altmann, J. (1974). Observational study of behaviour sampling methods. Behaviour, 49, 227-267. 
Ancrenaz, M., Guman, M., Marshall, A. J., Meijaard, E., Wich, S. A., \& Husson, S. (2016). Pongo pygmaeus. The IUCN red list of threatened species e T17975A17966347.

Arcadi, A. C., Robert, D., \& Boesch, C. (1998). Buttress drumming by wild chimpanzees: Temporal patterning, phrase integration into loud calls, and preliminary evidence for individual distinctiveness. Primates, 39(4), 505-518.

Arcadi, A. C., Robert, D., \& Mugurusi, F. (2004). A comparison of buttress drumming by male chimpanzees from two populations. Primates, 45(2), 135-139.

Aureli, F., Schaffner, C. M., Boesch, C., Bearder, S. K., Call, J., et al (2008). Fission fusion dynamics: New research frameworks. Current Anthropology, 49(4), 627-654.

Bakeman, R., \& Gottman, J. M. (1997). Observing interaction: An introduction to sequential analysis. Cambridge: Cambridge University Press.

Bard, K. A. (1992). Intentional behaviour and intentional communication in young free-ranging orangutans. Child Development, 63(5), 1186-1197.

Bard, K. A., \& Vauclair, J. (1984). The communicative context of object manipulation in ape and human adultinfant pairs. Journal of Human Evolution, 13, 181-190.

Bard, K. A., Dunbar, S., Maguire-Herring, V., Veira, Y., Hayes, K. G., \& McDonald, K. (2014). Gestures and social-emotional communicative development in chimpanzee infants. American Journal of Primatology, 76(1), 14-29.

Bard, K. A., Maguire-Herring, V., Tomonaga, M., \& Matsuzawa, T. (2017). The gesture 'touch': Does meaning-making develop in chimpanzees' use of a very flexible gesture? Animal Cognition, 1-16.

Bates, E., Camaioni, L., \& Volterra, V. (1975). The acquisition of performatives prior to speech. MerrillPalmer Quarterly of Behavior and Development, 21, 205-226.

Bermejo, M., \& Omedes, A. (1999). Preliminary vocal repertoire and vocal communication of wild bonobos (Pan paniscus) at Lilungu (Democratic Republic of Congo). Folia Primatologica, 70(6), 328-357.

Bolker, B. M., Brooks, M. E., Clark, C. J., Geange, S. W., Poulen, J. R., et al (2008). Generalized linear-mixed models: A practical guide for ecology and evolution. Trends in Ecology \& Evolution, 24(3), 127-135.

Byrne, R. W., \& Tanner, J. E. (2006). Gestural imitation by a gorilla: Evidence and nature of the capacity. International Journal of Psychology and Psychological Therapy, 6(2), 215-231.

Byrne, R. W., Cartmill, E., Gentry, E., Graham, K. E., Hobaiter, C., \& Tanner, J. (2017). Great ape gestures: Intentional communication with a rich set of innate signals. Animal Cognition, 20(4), 755-769.

Caeiro, C. C., Waller, B. M., Zimmermann, E., Burrows, A. M., \& Davila-Ross, M. (2013). OrangFACS: A muscle-based facial movement coding system for orangutans (Pongo spp.). International Journal of Primatology, 34(1), 115-129.

Call, J., \& Tomasello, M. (2007). Ape gestures and the origins of language. In J. Call \& M. Tomasello (Eds.), The gestural communication of apes and monkeys (pp. 221-239). Mahwah: Lawrence Erlbaum Associates.

Cant, J. G. (1992). Positional behavior and body size of arboreal primates: A theoretical framework for field studies and an illustration of its application. American Journal of Physical Anthropology, 88(3), 273-283.

Cartmill, E. A. (2008). Gestural communication in orangutans (Pongo pygmaeus and Pongo abelii): $A$ cognitive approach. $\mathrm{PhD}$ thesis, University of St Andrews.

Cartmill, E. A., \& Byrne, R. W. (2007). Orangutans modify their gestural signalling according to their audience's comprehension. Current Biology, 17(15), 1345-1348.

Cartmill, E. A., \& Byrne, R. W. (2010). Semantics of primate gestures: Intentional meanings of orangutan gestures. Animal Cognition, 13(6), 793-804.

Cheney, D. L., \& Seyfarth, R. M. (2018). Flexible usage and social function in primate vocalizations. Proceedings of the National Academy of Sciences of the USA, 115, 1974-1979. https://doi.org/10.1073 /pnas.1717572115.

Crockford, C., \& Boesch, C. (2005). Call combinations in wild chimpanzees. Behaviour, 142(4), 397-421.

Crockford, C., Wittig, R. M., Mundry, R., \& Zuberbühler, K. (2012). Wild chimpanzees inform ignorant group members of danger. Current Biology, 22(2), 142-146.

Crockford, C., Wittig, R. M., \& Zuberbühler, K. (2015). An intentional vocalization draws others' attention: A playback experiment with wild chimpanzees. Animal Cognition, 18, 581-591.

Crockford, C., Wittig, R. M., \& Zuberbühler, K. (2017). Vocalizing in chimpanzees is influence by socialcognitive processes. Science Advances, 3, e1701742.

Cudmore, R. J., \& Galdikas, B. M. F. (2012). Gestural flexibility in rehabilitant Bornean orangutans (Pongo pygmaeus) at the orangutan care center and quarantine in the state of Kalimantan Tengah. https://www. academia.edu/4472060/Gestural_Flexibility_in_Rehabilitant_Bornean_Orangutans. Accessed 19 June 2019.

Davis, J. T., Mengersen, K., Abram, N. K., Ancrenaz, M., Wells, J. A., \& Meijaard, E. (2013). It's not just conflict that motivated killing of orangutans. PLoS One, 8(10), 1-11. 
de Waal, F. B. M. (1988). The communicative repertoire of captive bonobos (Pan paniscus), compared to that of chimpanzees. Behaviour, 106(3), 183-251.

Delgado Jr., R. A., \& van Schaik, C. P. (2000). The behavioral ecology and conservation of the orangutan (Pongo pygmaeus): A tale of two islands. Evolutionary Anthropology, 9, 201-218.

Delgado, R. A., Lameira, A., Davila Ross, M., Husson, S. J., Morrogh-Bernard, H. C., \& Wich, S. A. (2009). Geographical variation in orangutan long calls. In S. A. Wich, S. S. U. Atmoko, T. M. Setia, C. P. van Schaik (Eds.), Orangutans: Geographic variation in behavioral ecology and conservation (pp 215-224). Oxford: Oxford University Press.

Estrada, A., Garber, P. A., Ryalnds, A. B., Roos, C., Fernandez-Duque, E., et al (2017). Impending extinction crisis of the world's primates: Why primates matter. Science Advances, 3(1), e1600946.

Fontaine, B., Moisson, P. Y., \& Wickings, E. J. (1995). Observations of spontaneous tool making and tool use in a captive group of western lowland gorillas (Gorilla gorilla gorilla). Folia Primatologica, 65(4), 219-223.

Fröhlich, M., Wittig, R. M., \& Pika, S. (2016a). Play-solicitation gestures in chimpanzees in the wild: Flexible adjustment to social circumstances and individual matrices. Royal Society Open Science, 3, 160278.

Fröhlich, M., Wittig, R. M., \& Pika, S. (2016b). Should I stay or should I go? Initiation of joint travel in mother-infant dyads of two chimpanzees communities in the wild. Animal Cognition, 19, 483-500.

Fröhlich, M., Kuchenbuch, P., Müller, G., Fruth, B., Furuichi, T., Wittig, R. M., \& Pika, S. (2016c). Unpeeling the layers of language: Bonobos and chimpanzees engage in cooperative turn-taking sequences. Scientific Reports, 6. https://doi.org/10.1038/srep25887.

Fröhlich, M., Müller, G., Zeiträg, R. W., \& Pika, S. (2017). Gestural development of chimpanzees in the wild: The impact of interactional experience. Animal Behaviour, 134, 271-282.

Galdikas, B. M. F. (1985). Orangutan sociality at Tanjung Putting. American Journal of Primatology, 9, 101-119.

Galdikas, B. M. F. (1988). Orangutan diet, range, and activity at Tanjung Puting, Central Borneo. International Journal of Primatology, 9(1), 1-35.

Gebo, D. L. (1992). Plantigrady and foot adaptation in African apes: Implications for hominid origins. American Journal of Physical Anthropology, 89(1), 29-58.

Genty, E., \& Byrne, R. W. (2010). Why do gorillas make sequences of gestures? Animal Cognition, 13, $287-301$.

Genty, E., \& Zuberbühler, K. (2014). Spatial reference in a bonobo gesture. Current Biology, 24, 1601-1605.

Genty, E., Breuer, T., Hobaiter, C., \& Byrne, R. W. (2009). Gestural communication of the gorilla (Gorilla gorilla): Repertoire, intentionality and possible origins. Animal Cognition, 12, 527-546.

Genty, E., Clay, Z., Hobaiter, C., \& Zuberbühler, K. (2014). Multi-modal use of a socially directed call in bonobos. PLoS One, 9(1), e84738.

Genty, E., Neumann, C., \& Zuberbühler, K. (2015). Complex patterns of signalling to convey different social goals of sex in bonobos, Pan paniscus. Scientific Reports, 5, e16135.

Goodall, J. (1986). The chimpanzees of Gombe: Patterns of behaviour. Cambridge: Harvard University Press.

Goossens, B., Chikhi, L., Ancrenaz, M., Lackman-Ancrenaz, I., Andau, P., \& Bruford, M. W. (2006). Genetic signature of anthropogenic population collapse in orang-utans. PLoS Biology, 4(2), 285-291.

Graham, K. E., Furuichi, T., \& Byrne, R. W. (2017). The gestural repertoire of the wild bonobo (Pan paniscus): A mutually understood communication system. Animal Cognition, 20(2), 171-177.

Graham, K. E., Hobaiter, C., Ounsley, J., Furuichi, T., \& Byrne, R. W. (2018). Bonobo and chimpanzee gestures overlap extensively in meaning. PLoS Biology, 16, e2004825.

Gruber, T. (2014). Wild-Born Orangutans (Pongo abelii) Engage in Triadic Interactions During Play. International Journal of Primatology, 35(2), 411-424.

Halina, M., Rossano, F., \& Tomasello, M. (2013). The ontogenetic ritualization of bonobo gestures. Animal Cognition, 16(4), 653-666.

Hardus, M. E., Lameira, A. R., van Schaik, C. P., \& Wich, S. A. (2009). Tool use in wild orang-utans modifies sound production: A functionally deceptive innovation? Proceedings of the Royal Society B: Biological Sciences, 276(1673), 3689-3694.

Hauser, M. D., \& Wrangham, R. W. (1987). Manipulation of food calls in captive chimpanzees. Folia Primatologica, 48(3-4), 207-210.

Hebert, P. L., \& Bard, K. A. (2000). Orangutan use of vertical space in an innovative habitat. Zoo Biology, 19(4), 239-251.

Hobaiter, C., \& Byrne, R. W. (2011a). The gestural repertoire of the wild chimpanzee. Animal Cognition, 14(5), 745-767.

Hobaiter, C., \& Byrne, R. W. (2011b). Serial gesturing by wild chimpanzees: Its nature and function for communication. Animal Cognition, 14(5), 827-838.

Hobaiter, C., \& Byrne, R. W. (2014). The meanings of chimpanzee gestures. Current Biology, 24(14), 1596-1600.

Hobaiter, C., \& Byrne, R. W. (2017). What is a gesture? A meaning-based approach to defining gestural repertoires. In Neuroscience \& Biobehavioral Reviews (Vol. 82, pp. 3-12). 
Hobaiter, C., Byrne, R. W., \& Zuberbühler, K. (2017). Wild chimpanzees' use of single and combined vocal and gestural signals. Behavioral Ecology and Sociobiology, 71, 96.

Husson, S., Wich, S. A., Marshall, A. J., Dennis, R. D., Ancrenaz, M., et al. (2009). Orangutan distribution, density, abundance and impacts of disturbance. In S. A. Wich, S. S. Utami Atmokim, T. M. Setia, \& C. P. van Schaik (Eds.), Orangutans: Geographic variation in behavioural ecology and conservation (pp. $77-$ 96). Oxford Scholarship Online.

Jaeggi, A. V., Van Noordwijk, M. A., \& Van Schaik, C. P. (2008). Begging for information: Mother-offspring food sharing among wild bornean orangutans. American Journal of Primatology, 70, 533-541.

Kersken, V., Gómez, J.-C., Liszkowski, U., Soldati, A., \& Hobaiter, C. (2018). A gestural repertoire of 1- to 2year old human children: In search of the ape gestures. Animal Cognition. https://doi.org/10.1007/s10071018-1213-z.

Kita, S., Van Gijn, I., \& Van der Hulst, H. (1997). Movement phases in signs and co-speech gestures, and their transcription by human coders. In I. Wachsmuth \& M. Fröhlich (Eds.), Gesture and sign language in human-computer interaction. Lecture notes in computer science (Vol. 1371). Berlin and Heidelberg: Springer-Verlag.

Lameira, A. R., Hardus, M. E., Nouwen, K. J. J. M., Topelbery, E., Delgado, R., et al (2013). Populationspecific use of the same tool-assisted alarm call between two wild orangutan populations (Pongo pygmaeus wurmbii) indication functional arbitrariness. PLoS One, 8(7), e69749.

Lameira, A. R., Hardus, M. E., Bartlett, A. M., Shumaker, R. W., Wich, S. A., \& Menken, S. B. (2015). Speech-like rhythm in a voiced and voiceless orangutan call. PLoS One, 10(1), e116136.

Laporte, M. N. C., \& Zuberbühler, K. (2011). The development of a greeting signal in wild chimpanzees. Developmental Science, 14, 1220-1234.

Leavens, D. A., Russell, J. L., \& Hopkins, W. D. (2005a). Intentionality as measured in the persistence and elaboration of communication by chimpanzees (Pan troglodytes). Child Development, 76(1), 291-306.

Leavens, D. A., Hopkins, W. D., \& Bard, K. A. (2005b). Understanding the point of chimpanzee pointing: Epigenesist and ecological validity. Current Directions in Psychological Science, 14(4), 185-189.

Liebal, K., Pika, S., Call, J., \& Tomasello, M. (2004a). To move or not to move: How apes adjust to attentional state of others. Interaction Studies, 5(2), 199-219.

Liebal, K., Call, J., \& Tomasello, M. (2004b). Use of gesture sequences in chimpanzees. American Journal of Primatology, 64, 377-396.

Liebal, K., Pika, S., \& Tomasello, M. (2006). Gestural communication of orangutans (Pongo pygmaeus). Gesture, 6(1), 1-38.

Liebal, K., Waller, B. M., \& Slocombe, K. E. (2011). The language void: The need for multimodality in primate communication research. Animal Behaviour, 81, 919-924.

Lonsdorf, E. V., Ross, S. R., Linick, S. A., Milstein, M. S., \& Melber, T. N. (2009). An experimental investigation of tool use in chimpanzees and gorillas. Animal Behaviour, 77(5), 1119-1126.

Mackinnon, J. (1974). The behaviour and ecology of wild orang-utans (Pongo pygmaeus). Animal Behaviour, $22,3-74$

Manduell, K. L., Morrogh-Bernard, H. C., \& Thorpe, S. K. S. (2011). Locomotor behavior of wild orangutans (Pongo pygmaeus wurmbii) in disturbed peat swamp forest, Sabangau, Central Kalimantan, Indonesia. American Journal of Physical Anthropology, 145, 348-359.

McHugh, M. L. (2012). Interrater reliability: The kappa statistic. Biochemia Medica, 22(3), 276-282.

Meijaard, E., Welsh, A., Ancrenaz, M., Wich, S., Nijman, V., et al (2010). Declining orangutan encounter rates from Wallace to the present suggest the species was once more abundant. PLoS One, 5(8), 1-9.

Meijaard, E., Buchori, D., Hadiprakarsa, Y., Utami-Atmoko, S. S., Nurcahyo, A., et al (2011). Quantifying killing of orangutans and human-orangutan conflict in Kalimantan, Indonesia. PLoS One, 6(11), 1-10.

Mitani, J. C. (1985). Mating behaviour of male orangutans in the Kutai game reserve, Indonesia. Animal Behaviour, 33(2), 392-402.

Mitani, J. C., Grether, G. F., Rodman, P. S., \& Priatna, D. (1991). Association among wild orang-utans: Sociality, passive aggregations or chance? Animal Behaviour, 42, 33-46.

Mitani, J. C., Hunley, K. L., \& Murdoch, M. E. (1999). Geographic variation in the calls of wild chimpanzees: A reassessment. American Journal of Primatology, 47, 133-151.

Moore, R. (2014). Ape gestures: Interpreting chimpanzee and bonobo minds. Current Biology, 24, R645-R647.

Morrogh-Bernard, H. C., Husson, S. J., \& McLardy, C. (2002). Orang-utan data collection standardisation. In Orang-utan Culture Workshop, San Anselmo, p. 13.

Morrogh-Bernard, H., Husson, S., Page, S. E., \& Rieley, J. O. (2003). Population status of the Bornean orangutan (Pongo pygmaeus) in the Sebangau peat swamp forest, Central Kalimantan, Indonesia. Biological Conservation, 110, 141-152.

Nishida, T. (1968). The social group of wild chimpanzees in the Mahale Mountains. Primates, 9, 167-224. 
Nowak, M. G., Rianti, P., Wich, S. A., Meijaard, E., \& Fredriksson, G. (2017). Pongo tapanuliensis. The IUCN red list of threatened species.

Oishi, M., Ogihara, N., Endo, H., Ichihara, N., \& Asari, M. (2009). Dimensions of forelimb muscles in orangutans and chimpanzees. Journal of Anatomy, 215(4), 373-382.

Perlman, M., Tanner, J. E., \& King, B. J. (2012). A mother gorilla's variable use of touch to guide her infant. In S. Pika \& K. Liebal (Eds.), Developments in primate gesture research (pp. 55-72). Amsterdam: John Benjamins.

Peters, H. H. (2001). Tool use to modify calls by wild orang-utans. Folia Primatologica, 72, 242-244.

Pika, S., Liebal, K., \& Tomasello, M. (2003). Gestural communication in young gorillas (Gorilla gorilla): Gestural repertoire, learning, and use. American Journal of Primatology, 60, 95-111.

Pika, S., Liebal, K., \& Tomasello, M. (2005). Gestural communication in subadult bonobos (Pan paniscus): Repertoire and use. American Journal of Primatology, 65, 39-61.

Plooij, F. X. (1978). Some basic traits of language in wild chimpanzees? In A. Lock (Ed.), Action, gesture and symbol (pp. 111-131). London: Academic Press.

Pollick, A. S., \& de Waal, F. B. M. (2007). Ape gestures and language evolution. Proceedings of the National Academy of Sciences of the USA, 104, 8184-8189.

Poss, S. R., Kuhar, C., Stoinski, T. S., \& Hopkins, W. D. (2006). Differential use of attentional and visual communicative signalling by orangutans (Pongo pygmaeus) and gorillas (Gorilla gorilla) in response to the attentional status of a human. American Journal of Primatology, 68(10), 978-992.

Pozzi, L., Hodgson, J. A., Burrell, A. S., Sterner, K. N., Raaum, R. L., \& Disotell, T. R. (2014). Primate phylogenetic relationships and divergence dates inferred from complete mitochondrial genomes. Molecular Phylogenetics and Evolution, 75, 165-183.

Price, E. P., \& Stoinski, T. S. (2007). Group size: Determinants in the wild and implications for the captive housing of wild mammals in zoos. Applied Animal Behaviour Science, 103(3-4), 255-264.

Rijksen, H. (1978). A field study on Sumatran orangutans (Pongo pygmaeus abelli, Lesson 1827): Ecology, behaviours and conservation. Wageningen: Veenman.

Robbins, M. M., \& Robbins, A. M. (2018). Variation in the social organization of gorillas: Life history and socioecological perspectives. Evolutionary Anthropology, 27(5), 218-233.

Roberts, A. I., Vick, S.-J., \& Buchanan-Smith, H. M. (2012). Usage and comprehension of manual gestures in wild chimpanzees. Animal Behaviour, 84, 459-470.

Salmi, R., Hammerschmidt, K., \& Doran-Sheehy, D. M. (2013). Western gorilla vocal repertoire and contextual use of vocalizations. Ethology, 119(10), 831-847.

Schel, A. M., Machanda, Z., Townsend, S. W., Zuberbühler, K., \& Slocombe, K. E. (2013a). Chimpanzee food calls are directed at specific individuals. Animal Behaviour, 86(5), 955-965.

Schel, A. M., Townsend, S. W., Machanda, Z., Zuberbühler, K., \& Slocombe, K. (2013b). Chimpanzee alarm call production meets key criteria for intentionality. PLoS One, 8(10), e76674.

Schneider, C., Call, J., \& Liebal, K. (2012). Onset and early use of gestural communication in nonhuman great apes. American Journal of Primatology, 74, 102-113.

Seyfarth, R. M., \& Cheney, D. L. (2017). The origin of meaning in animal signals. Animal Behaviour, 124, $339-346$.

Singleton, I., Wich, S., Husson, S., Stephens, S., Utami-Atmoko, S. S., Leighton, M., et al. (2004). Orangutan: Population and habitat viability assessment. Available at: http://awsassets.panda. org/downloads/orangutanphva04_lowres.pdf. Accessed 19 June 2019.

Slocombe, K. E., \& Zuberbühler, K. (2007). Chimpanzees modify recruitment screams as a function of audience composition. Proceedings of the National Academy of Sciences of the USA, 104(43), 17228-17233.

Smith, J. J. (2009). Orangutan-human interaction in rehabilitation: Orangutan contribution to interaction and conflict. MSc thesis, York University.

Tanner, J. E., \& Byrne, R.W. (1999). Spontaneous gestural communication in captive lowland gorillas. In: S. T. Parker, R. W. Mitchell, \& L. H. Miles (Eds.) The mentalities of gorillas and orang-utans in comparative perspective (pp 211-240). Cambridge: Cambridge University Press.

Tanner, J. E., Patterson, F. G., \& Byrne, R. W. (2006). The development of spontaneous gestures in zoo-living gorillas and sign-taught gorillas: From action and location to object representation. Journal of Developmental Processes, 1, 69-102.

Thorpe, S. K. S., \& Crompton, R. H. (2005). Locomotor ecology of wild orangutans (Pongo pygmaeus abelii) in the Gunung Leuser ecosystem, Sumatra, Indonesia: A multivariate analysis using log-linear modelling. American Journal of Physical Anthropology, 127, 58-78.

Thorpe, S. K. S., \& Crompton, R. H. (2006). Orangutan positional behavior and the nature of arboreal locomotion in Hominoidea. American Journal of Physical Anthropology, 131(3), 1-18.

Tomasello, M., George, B. L., Kruger, A. C., Jeffrey, M., \& Evans, A. (1985). The development of gestural communication in young chimpanzees. Journal of Human Evolution, 14, 175-186. 
Tomasello, M., Gust, D., \& Frost, G. T. (1989). A longitudinal investigation of gestural communication in young chimpanzees. Primates, 30, 35-50.

Tomasello, M., Call, J., Nagell, K., Olguin, R., \& Carpenter, M. (1994). The learning and use of gestural signals by young chimpanzees: A trans-generational study. Primates, 35(2), 137-154.

Tomasello, M., Call, J., Warren, J., Frost, G. T., Carpenter, M., \& Nagell, K. (1997). The Ontogeny of Chimpanzee Gestural Signals: A Comparison Across Groups and Generations. Evolution of Communication, 1(2), 223-259.

van Adrichem, G. G. J., Utami, S. S., Wich, S. A., van Hooff, J. A. R. A. M., \& Sterck, E. H. M. (2006). The development of wild immature sumatran orangutans (pongo abelii) at Ketambe. Primates, 47, 300-309.

Van Noordwijk, M. A., \& Van Schaik, C. P. (2005). Development of ecological competence in Sumatran orangutans. American Journal of Physical Anthropology, 127, 79-94.

van Schaik, C. P. (1999). The socioecology of fission-fusion sociality in orangutans. Primates, 40(1), 69-86.

van Schaik, C. P. (2003). Orangutan cultures and the evolution of material culture. Science, 299, 102-105.

van Schaik, C. P., Van Noordwijk, M. A., \& Wich, S. A. (2006). Innovation in wild Bornean orangutans (Pongo pygmaeus wurmbii). Behaviour, 143(7), 839-876.

Waller, B. M., Caeiro, C. C., \& Davila-Ross, M. (2015). Orangutans modify facial displays depending on recipient attention. PeerJ, 3, e827.

Wich, S. A., Utami-Atmoko, S. S., Mitra Setia, T., Rijksen, H. D., Schurmann, C., et al (2004). Life history of wild Sumatran orangutans (Pongo abelii). Journal of Human Evolution, 47, 385-398.

Wich, S. A., Meijaard, E., Marshall, A. J., Husson, S., Ancrenaz, M., et al (2008). Distribution and conservation status of the orang-utan (Pongo spp.) on Borneo and Sumatra: How many remain? Oryx, 42(3), 329-339.

Wich, S. A., Krutzen, M., Lameira, A. R., Nater, A., Arora, N., et al (2012). Call cultures in orang-utans? PLoS One, 7(5), 1-9.

Wilke, C., Kavanagh, E., Donnellan, E., Waller, B. M., Machanda, Z. P., \& Slocombe, K. E. (2017). Production of and responses to unimodal and multimodal signals in wild chimpanzees, Pan troglodytes schweinfurthii. Animal Behaviour, 123, 305-316.

\section{Affiliations}

\section{Andrea Knox ${ }^{1} \cdot$ Joey Markx ${ }^{2,3} \cdot$ Emma How $^{1} \cdot$ Abdul Azis $^{3} \cdot$ Catherine Hobaiter $^{4}$. Frank J. F. van Veen ${ }^{1} \cdot$ Helen Morrogh-Bernard ${ }^{1,3}$}

Catherine Hobaiter

clh42@st-andrews.ac.uk

1 Centre for Ecology and Conservation, College of Life and Environmental Sciences, University of Exeter, Cornwall TR10 9EZ, UK

2 Wageningen University, 6708 PB Wageningen, The Netherlands

3 Borneo Nature Foundation, Bukit Raya, Palangkaraya, Central Kalimantan 73112, Indonesia

4 School of Psychology and Neuroscience, University of St. Andrews, St. Andrews KY16 9JP, UK 